\title{
DETERMINATION OF FORCE CAUSED BY HEATING OF RING-TYPE PRODUCTS IN FLASH-BUTT WELDING
}

\author{
A.V. MOLTASOV, K.V. GUSHCHIN, I.N. KLOCHKOV, P.N. TKACH and A.I. TARASENKO \\ E.O. Paton Electric Welding Institute, NASU \\ 11 Bozhenko Str., 03680, Kiev, Ukraine. E-mail: office@paton.kiev.ua
}

\begin{abstract}
In flash-butt welding of products of a closed shape the force, which welding machine should provide for high-quality formation of welded joint in a solid phase, is determined not only by upsetting force but also by force spent for bending the part itself, and by force caused by heating of shunting part. Therefore, when choosing the equipment for welding of any product of closed shape it is necessary to determine the total force, which welding machine should provide. The experimental measurements of temperature in different characteristic points at the final stage of the process of FBW of the ring of steel 20 in machine K-724 were carried out. It was established that the temperature in the shunting part is changed both along the circumferential as well as along the radial coordinate. The existing procedure for description of temperature field was improved so that in determination of the Fourier coefficients not only the experimental data were used, but also the data obtained by computer modeling. Basing on the postulates of the proposed model the function of general form was obtained, which allows determining the temperature at any point of the shunting part using an unlimited number of terms of approximated series. The calculation of power parameters of FBW with pulsed flashing of the investigated ring was carried out. As a result, it was established that the force caused by heating of the shunting part, amounted to $9.1 \%$ of the total force required for quality formation of the joint. The value of temperature force is connected with the value of equivalent temperature displacement. The estimated value of this displacement, corresponding to the proposed model, correlates well with the results of numerical modeling of temperature displacements in the welded billet. 11 Ref., 1 Table, 3 Figures.
\end{abstract}

$\boldsymbol{K} \boldsymbol{e} \boldsymbol{y} \boldsymbol{w} \boldsymbol{O} \boldsymbol{r} \boldsymbol{s}:$ flash-butt welding, ring-type products, shunting currents, temperature field, Fourier series, temperature force

The advantages of flash-butt welding (FBW) determine its wide application in manufacture of structural elements such as frame rings, bands, turntables, stiffening rings, wheel rims and other products of a closed shape [1].

At the E.O. Paton Electric Welding Institute a number of machines for FBW of ring-type products was developed, which are able to develop the force from several dozens to several thousands kilonewtons [2], and some of them have also limitations on the minimum inner diameter of the product being welded [3]. Therefore, the producer encounters often a difficult task to select the optimum equipment from the existing number of machines for welding the certain ring product.

In FBW of parts of an open shape the power parameters are determined by a specific upsetting pressure of material of the part and the area of its cross-section [4]. In the process of FBW of ring-type products the bending of the part itself and the shunting of electric current through it occur [5].

In work [6] it was proved that heating of the shunting part contributes to arising of thermal stresses, which affect the volume of the force required for formation of quality welded joint during FBW. However, the procedure of description of the temperature field, demonstrated in the present work, allows using a limited number of terms of the series, with the help of which it is not always possible to obtain the desired accuracy. Furthermore, no expression was given for the force generated by thermal stresses in the shunting part.

Therefore, the aim of this work is the improvement of the procedure for description of temperature field and force caused by heating of the shunting part.

The experimental measurements of temperatures were carried out during FBW of the ring of steel 20 with cross-section of $55 \times 25 \mathrm{~mm}^{2}$ and inner diameter of $270 \mathrm{~mm}$ (Figure 1, $a$ ) in five controllable points (Figure 1, b).

According to the results of measurements it was established that the temperature in the shunting part is changed both around the circumference $\theta$, as well as around the radial coordinate $r$. As the determination of force caused by heating of the shunting part is based on solving the relevant problems of theory of elasticity, it is necessary to preset the temperature as a continuous 

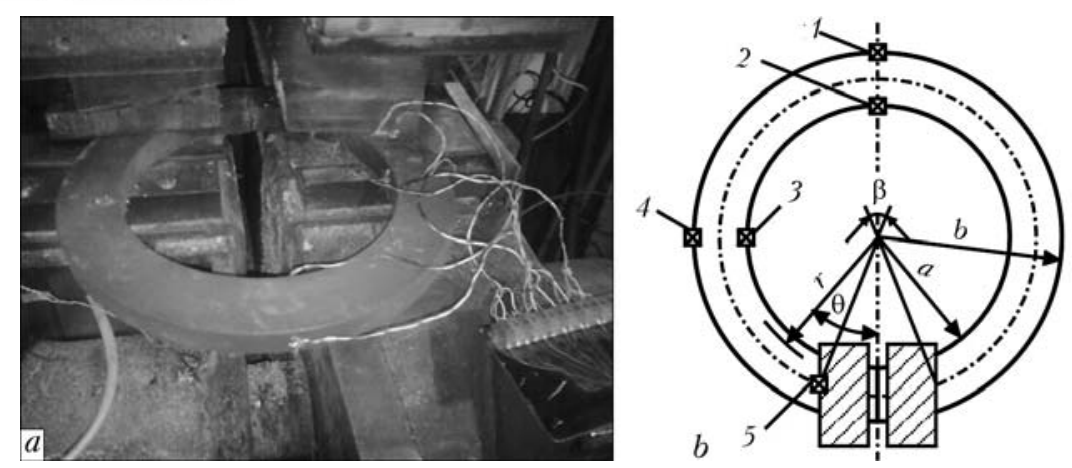

\begin{tabular}{|c|c|c|}
\hline $\begin{array}{c}\text { Number } \\
\text { of point }\end{array}$ & $\theta, \operatorname{deg}$ & $T,{ }^{\circ} \mathrm{C}$ \\
\hline 1 & $\pi$ & 460 \\
2 & $\pi$ & 510 \\
3 & $\pi / 2$ & 480 \\
4 & $\pi / 2$ & 450 \\
5 & $\approx \pi / 6$ & 130 \\
\hline
\end{tabular}

Figure 1. Ring workpiece in clamping devices of welding machine K-724 (a), and layout of points 1-5 (1-5) of temperature control $(b)$

function of the coordinates. In solving the problems in polar coordinates the most convenient for description of change in temperature is the even part of the Fourier series around the circumferential coordinate $\theta$ :

$$
T(\theta)=A_{0}+\sum_{1}^{n} A_{n} \cos n \theta .
$$

To determine the unknown Fourier coefficients $A_{n}$ it is necessary to create the system of equations for temperature values in the different points around the circumferential coordinate $\theta$ of the shunting part. As far as the experimental data allow presetting only three temperature values at the outer and inner diameters, namely, $T(\pi / 6), T(\pi / 2)$ and $T(\pi)$, the other ones can be determined by computer modeling of the temperature field (Figure 2,a). The number of equations of the system determines the accuracy of description of the temperature field. Using the first six terms of the series (Table) allows describing the temperature field with the accuracy of up to $3{ }^{\circ} \mathrm{C}$. You can be sure that the values of temperatures, taken from the diagram (Figure 2, $b)$, coincide with the results of computer modeling.

As is seen, the value of the coefficients decreases according to the absolute value, so the introduction of the following coefficients will not make a considerable amendment to the values of temperatures.

The change in the temperatures in the radial direction is determined from the differential equation of thermal conductivity [7]:

$$
\frac{1}{\chi} \frac{\partial T}{\partial t}=\frac{\partial^{2} T}{\partial r^{2}}+\frac{1}{r} \frac{\partial T}{\partial r}+\frac{1}{r^{2}} \frac{\partial^{2} T}{\partial \theta^{2}}
$$

Calculated Fourier coefficients in points $1-5$ acc. to Figure 1, $b$

\begin{tabular}{||l|c|c|c|c|c|c||}
\hline \hline Coefficient & $A_{0}$ & $A_{1}$ & $A_{2}$ & $A_{3}$ & $A_{4}$ & $A_{5}$ \\
\hline$T_{\text {in.dia }},{ }^{\circ} \mathrm{C}$ & 373 & -221 & -122.5 & -51 & -51 & -3 \\
\hline$T_{\text {out.dia }}{ }^{\circ} \mathrm{C}$ & 339 & -192 & -106.5 & -48 & -51 & -3 \\
\hline
\end{tabular}

where $\chi$ is the coefficient of thermal conductivity.

As far as the temperature field is considered at the moment when the temperature reaches its maximum value, but not its change in time, then the left side of equation (2) turns to zero (solution of such equation is given in work [6]).

As a result the function of general view was obtained corresponding to the proposed model, which allows determining the temperature at any point of the shunting part:

$$
T(r, \theta)=K_{0}=H_{0} \ln r+\sum_{1}^{n}\left(K_{n} r^{n}+\frac{H_{n}}{r^{n}}\right) \cos n \theta,
$$

where

$$
\begin{gathered}
K_{0}=\frac{A_{0}(a) \ln b-A_{0}(b) \ln a}{\ln b-\ln a} ; \\
K_{n}=\frac{A_{n}(b) b^{n}-A_{n}(a) a^{n}}{b^{2 n}-a^{2 n}} ; \\
H_{0}=\frac{A_{0}(b)-A_{0}(a)}{\ln b-\ln a} ; \\
H_{n}=\frac{a^{n} b^{n}}{b^{2 n}-a^{2 n}}\left[A_{n}(a) b^{n}-A_{n}(b) a^{n}\right] .
\end{gathered}
$$

(For procedure of determination of stresses caused by the presence of temperature field described by the Fourier series see works $[8,9]$.)

So, stress components have the following form:

$$
\begin{aligned}
\sigma_{r}= & B_{0} \frac{1}{r^{2}}+2 C_{0}+D_{0}(1+2 \ln r)+ \\
& +\left(2 B_{1} r-\frac{2 C_{1}}{r^{3}}+\frac{D_{1}}{r}\right) \cos \theta ; \\
\sigma_{\theta}= & -B_{0} \frac{1}{r^{2}}+2 C_{0}+D_{0}(3+2 \ln r)+ \\
& +\left(6 B_{1} r+\frac{2 C_{1}}{r^{3}}+\frac{D_{1}}{r}\right) \cos \theta ; \\
\tau_{r \theta} & =\left(2 B_{1} r-\frac{2 C_{1}}{r^{3}}+\frac{D_{1}}{r}\right) \sin \theta,
\end{aligned}
$$



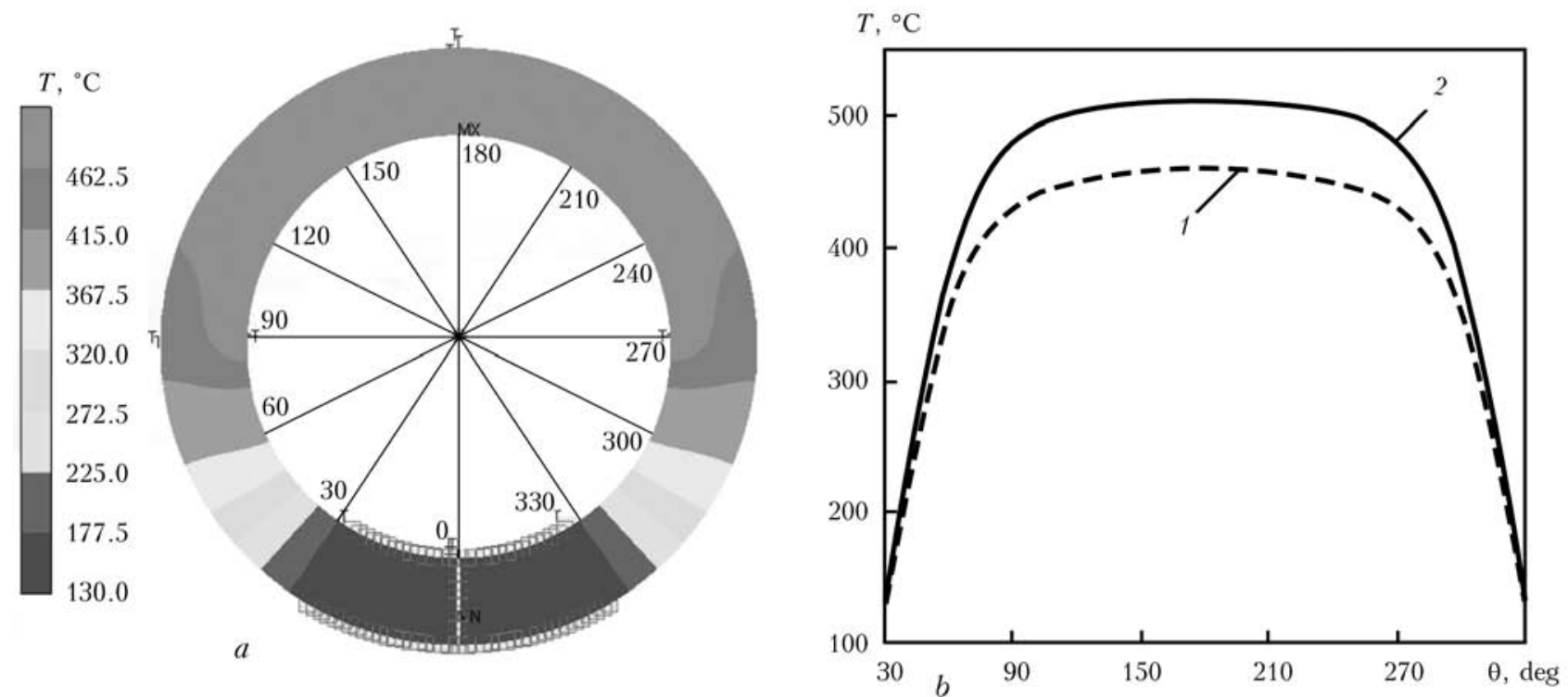

Figure 2. Temperature fields in the ring $(a)$, and diagrams of temperature distribution along the outer (1) and inner (2) diameter $(b)$

where

$$
\begin{gathered}
B_{0}=-\frac{\alpha E H_{0}}{2\left(b^{2}-a^{2}\right)} a^{2} b^{2} \ln \frac{b}{2} ; \quad B_{1}=\frac{\alpha E H_{1}}{4\left(a^{2}+b^{2}\right)} ; \\
C_{0}=\frac{\alpha E H_{0}}{4} \frac{b^{2} \ln b-a^{2} \ln a}{b^{2}-a^{2}}+\frac{\alpha E H_{0}}{8} ; \\
C_{1}=-\frac{\alpha E H_{1}}{4\left(a^{2}+b^{2}\right)} a^{2} b^{2} ; \\
D_{0}=\frac{\alpha E H_{0}}{4} ; \quad D_{1}=\frac{\alpha E H_{1}}{2},
\end{gathered}
$$

where $\alpha$ is the coefficient of linear expansion; $E$ is the modulus of elasticity of material.

The relation of the displacement components with the stress components was found in [10].

Therefore, stresses (5) in the closed ring are equivalent to circumferential displacement of the ring moving edge with a gap for the value of

$$
\delta_{\mathrm{t}}=-(2 \pi-\beta) \alpha\left(H_{0} \frac{a+b}{2}+H_{1}\right) .
$$

As far as in our case, according to (4), $H_{0}$ and $H_{1}$ are negative, then the displacement $\delta_{\mathrm{t}}$ is $\mathrm{di}^{-}$ rected towards the increase of coordinate $\theta$, i.e. is equal to increase of the gap.

In our case the temperature displacement amounted to $2.88 \mathrm{~mm}$. To confirm this result a numerical modeling of displacement fields in the ring workpiece was carried out during heating, being similar to that realized in the ring shunting part in FBW (Figure 3).

According to the results of numerical modeling it was established that the temperature move- ment of the left edge amounted to $3.04 \mathrm{~mm}$, that is $5.3 \%$ higher than the value obtained by analytical calculation according to formula (6), corresponding to the temperature field (3).

As far as this displacement is directed opposite from displacement of the moving clamping device of the welding machine, a part of the force is spent to overcome it. The relation between the displacement and the corresponding force was established in work [10]. Thus, to prevent the displacement (6) it is necessary to apply the force

$$
\begin{gathered}
P_{\mathrm{t}}=-\alpha E t \frac{2 \pi-\beta}{4 \pi} \times \\
\times\left(H_{0} \frac{\left(b^{2}-a^{2}\right)^{2}-4 a^{2} b^{2}}{2(a+b)\left(b^{2}-a^{2}\right)}+H_{1} \frac{a^{2}-b^{2}+\left(a^{2}+b^{2}\right) \ln \frac{b}{2}}{a^{2}+b^{2}}\right) .
\end{gathered}
$$

For the investigated ring the calculation of power parameters of FBW with pulsed flashing

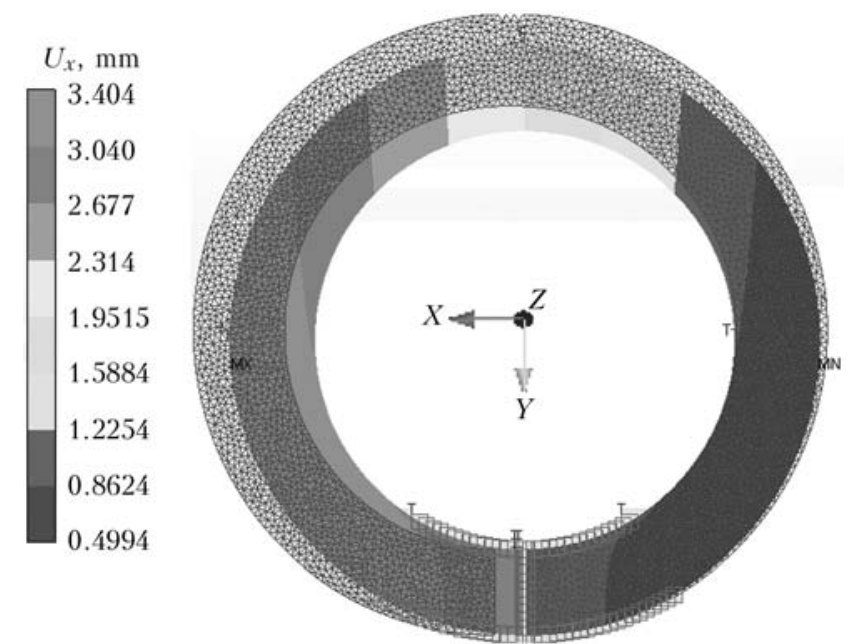

Figure 3. Field of displacements in the ring (mesh indicates the deformed state) 
was performed [11]. The force, spent for bending of the part, is determined by the formula obtained in $[10]$ :

$$
P_{\text {bend }}=-\frac{E \delta_{\Sigma} t}{4 \pi\left(a^{2}+b^{2}\right)}\left[a^{2}-b^{2}+\left(a^{2}+b^{2}\right) \ln \frac{b}{a}\right],
$$

where $\delta_{\Sigma}$ is the sum of the initial gap and allowances for flashing and upsetting.

As a result, it was established that the thermal force amounts to more than $9 \%$ of the total force, which the welding machine should provide to form the quality welded joint in solid phase.

The calculation of power parameters of FBW with pulsed flashing of the investigated ring was carried out at the following initial data: inner diameter $270 \mathrm{~mm}$; cross-section $F=55 \times$ $\times 25 \mathrm{~mm}^{2}$; specific upsetting pressure $40 \mathrm{MPa}$; modulus of elasticity $210 \mathrm{GPa}$; coefficient of linear expansion $1.4 \cdot 10^{-5} 1 / \mathrm{deg}$; initial gap $2 \mathrm{~mm}$; allowance for flashing $9 \mathrm{~mm}$; allowance for upsetting $7 \mathrm{~mm}$.

Obtained were the dummy displacement from heating $\delta_{\mathrm{t}}=2.88 \mathrm{~mm}$; thermal force $P_{\mathrm{t}}=14.8$ $\mathrm{kN}$; upsetting force $P_{\mathrm{ups}}=55 \mathrm{kN}$; bending force $P_{\text {bend }}=92.6 \mathrm{kN}$; total force $P_{\Sigma}==162.4 \mathrm{kN}$; $P_{\mathrm{t}} / P_{\Sigma}=9.1 \%$.

\section{Conclusions}

1. The procedure was improved, which allows describing the temperature field in the shunting part in FBW of ring-type workpiece in the form of even part of the Fourier series around the circumferential coordinate on the basis of discrete data obtained by experimental measurements and computer modeling.

2. In accordance with the postulates of the proposed model the function of general form was obtained, which allows determining the temperature at any point of the ring shunting part using unlimited number of series terms.

3 . For the first time an analytical expression was obtained for determination of the force acting on the butt caused by heating of the shunting part. For the ring of steel 20 with inner diameter of $270 \mathrm{~mm}$ and cross-section of $55 \times 25 \mathrm{~mm}^{2}$ the power parameters of FBW using pulsed flashing were calculated. As a result, it was established that the force caused by heating of the shunting part amounts to $9.1 \%$ of the total force, which welding machine should provide.

1. Pavlichenko, V.S. (1964) Resistance welding of closed-shape products. Moscow: Mashinostroenie.

2. Kuchuk-Yatsenko, S.I. (1992) Flash butt welding. Kiev: Naukova Dumka.

3. Kuchuk-Yatsenko, S.I, Chvertko, P.N., Semyonov, L.A. et al. (2013) Flash butt welding of products of high-strength alloys based on aluminium. The Paton Welding J., 7, 2-6.

4. Gelman, A.S. (1952) Technology of electric resistance welding. Moscow: Mashgiz.

5. Kabanov, N.S. (1973) Welding on resistance machines. Moscow: Vysshaya Shkola.

6. Moltasov, A.V., Samotryasov, S.M., Knysh, V.V. et al. (2014) Influence of non-uniformity of heating on upsetting force value and forging time in flash-butt welding of flat ring. The Paton Welding J., 10, 11-14.

7. Karslou, G., Eger, D. (1964) Thermal conductivity of solids. Moscow: Nauka.

8. Timoshenko, S.P., Goodier, J. (1975) Theory of elasticity. Moscow: Nauka.

9. Boli, B., Ueiner, J. (1964) Theory of temperature stresses. Moscow: Mir.

10. Chvertko, P.N., Moltasov, A.V., Samotryasov, S.M. (2014) Calculation of upsetting force in flash butt welding of closed-shape products. The Paton Welding J., 1, 46-50.

11. Kuchuk-Yatsenko, S.I., Didkovsky, V.A., Bogorsky, M.V. et al. Method of flash butt welding. Pat. 46820 Ukraine. Publ. 17.06.2002.

Received 11.02.2015 